\title{
FONOAUDIOLOGIA E ONCOLOGIA: RELATO DE EXPERIÊNCIA DE EDUCAÇÃO EM SAÚDE NA ATENÇÃO PRIMÁRIA À SAÚDE
}

\author{
SPEECH THERAPY AND ONCOLOGY: REPORT OF EXPERIENCE IN \\ HEALTH EDUCATION IN PRIMARY HEALTH CARE
}

\author{
Maria Júlia Galindo Soares ${ }^{1}$ \\ Paôlla Gabrielly Antas Lunguinho Dantas ${ }^{2}$ \\ Andreia da Silva Morais ${ }^{3}$ \\ Janaína Von Söhsten Trigueiro ${ }^{4}$
}

RESUMO: OBJETIVO: Sensibilizar a comunidade sobre a Fononcologia, buscando prevenir novos casos de câncer e evidenciar a importância do fonoaudiólogo no cuidado ao paciente oncológico. MÉTODO: Relato de experiência de uma ação educativa alusiva ao dia mundial do combate ao câncer. Atividade realizada por estudantes do Estágio Supervisionado em Saúde Coletiva, componente curricular do Curso de Graduação em Fonoaudiologia da Universidade Federal da Paraíba (UFPB). A mesma ocorreu no mês de fevereiro do corrente ano, na sala de espera de uma Unidade de Saúde da Família (USF) situada na área de abrangência do Distrito Sanitário V, do município de João Pessoa-PB. RESULTADOS: A atividade educativa realizada na USF ampliou não somente o conhecimento dos usuários, mas também de cada estagiário, sobretudo acerca da ausência de saberes em relação à Fonoaudiologia. Ainda há muito que fazer para enaltecer essa profissão tão multifacetada na Atenção Primária à Saúde (APS). O contato com os usuários possibilitou novos olhares e saberes. Ouvi-los, conhecer mais sobre eles, suas realidades e dificuldades dá sentido a uma ação que visa a troca, a partilha. $E$ assim, desconstruindo paradigmas entre comunidade e universidade, criou-se um vínculo de confiança, fortalecendo a prática do Estágio, edificando o fazer saúde. CONCLUSÃO: A experiência de formar um grupo heterogêneo, no qual se pôde empregar a empatia e a humanização nas entrelinhas da temática que estava sendo

\footnotetext{
1 Graduanda do Curso de Fonoaudiologia da Universidade Federal da Paraíba - UFPB, juliagalindo8@gmail.com.

2 Graduanda do Curso de Fonoaudiologia da Universidade Federal da Paraíba - UFPB, paollagabrielly19@gmail.com.

Graduanda do Curso de Fonoaudiologia da Universidade Federal da Paraíba - UFPB, andreia.sm10@gmail.com.

4 Doutora em Enfermagem e Professora Adjunta do Departamento de Fonoaudiologia da Universidade Federal da Paraíba - UFPB, janavs_23@hotmail.com.
} 
abordada, superaram as expectativas de ambas as partes envolvidas nesse processo de aprendizado contínuo.

Descritores: Fonoaudiologia, Oncologia, Educação em Saúde, Atenção Primária à Saúde.

ABSTRACT: OBJECTIVE: To sensitize the community about speech therapy and oncology, seeking to prevent new cases of cancer and highlight the importance of the speech therapist in the care of cancer patients. METHOD: Experience report of an educational action alluding to the World Day to Combat Cancer. Activity carried out by students of the Supervised Internship in Public Health, curricular component of the Undergraduate Course in Speech Therapy at the Federal University of Paraiba (UFPB). The same occurred in February this year, in the waiting room of a Family Health Unit (USF), located in the coverage area of the Sanitary District $V$, in the city of João Pessoa-PB. RESULTS: An educational activity carried out at the primary health care included not only the knowledge of the users, but also of each trainee, mainly about the absence of flavors in relation to Speech Therapy. There is still a lot to do to improve this profession, which is so multifaceted in Primary Health Care (APS). The contact with the users enabled new looks and sabers. Listening, knowing more about them, their realities and difficulties gives meaning to an action that aims to exchange, a sharing. And so, deconstructing paradigms between community and university, it created a bond of trust, strengthened the practice of the internship, built or made health. CONCLUSION: The experience of forming a heterogeneous group, without qualifying to use empathy and humanization between the lines of the theme that was being addressed, exceeded the expectations of resources as part of the continuous training process.

Keywords: Speech Therapy; Oncology; Health Education; Primary Health Care. 


\section{INTRODUÇÃO}

A educação em saúde deve perpassar em todo e qualquer cuidado prestado à população na Atenção Primária à Saúde (APS). Dentre as diversas atividades desenvolvidas pelos profissionais, esta busca estimular o autocuidado dos usuários por meio do compartilhamento de conhecimentos e experiências. Geralmente ocorre na sala de espera e pode subsidiar ações tanto de promoção da saúde quanto da prevenção de doenças (SANTOS; BORGES, 2016).

O espaço da sala de espera é onde a comunidade inicialmente é acolhida. As pessoas que se encontram nesse local às vezes nem se conhecem, porém terminam expressando bem como partilhando suas necessidades e problemas de saúde. É por essa razão que quando há uma atividade educativa pela iniciativa dos profissionais de saúde, comumente forma-se um grupo repleto de especificidades, tornando esse ambiente propício para reflexões acerca dos mais diversos temas. Esse momento promove um encontro singular entre o senso comum e o saber científico, gerando a disseminação de informações relevantes para o cotidiano de todos (LIMEIRA et al., 2014).

Dentre às variadas temáticas que podem ser abordadas na sala de espera por meio da educação em saúde está o câncer. É definido como um conjunto de doenças que tem em comum o crescimento desordenado de células, que tendem a ser muito agressivas e incontroláveis e podem espalhar-se para outras regiões do corpo (INCA, 2019). Vale ressaltar que trabalhar tal assunto na APS pode estimular a celeridade do diagnóstico e a procura mais rápida pelo serviço de saúde, o que acarreta em maiores chances de cura e qualidade de vida.

Durante o Estágio Supervisionado em Saúde Coletiva do curso de Graduação em Fonoaudiologia da Universidade Federal da Paraíba (UFPB), há a oportunidade dos discentes irem ao campo prático na APS e vivenciarem as várias atividades que podem acontecer na Unidade de Saúde da Família (USF). Uma delas é a educação 
em saúde, quando foi escolhida a temática sobre a relação da Fonoaudiologia e Oncologia.

Salienta-se que foi na década de 1990 que o fonoaudiólogo ampliou sua atuação nos casos oncológicos de cabeça e pescoço, intervindo nas intercorrências alimentares, nos comprometimentos de fala, de mímica facial e de motricidade oral, além das sequelas vocais na qual foi seu principal campo de ação (VICENTE, 2000). A reabilitação fonoaudiológica se faz necessária também junto aos pacientes oncológicos que foram submetidos à radiação, pois são descritas sequelas presentes após estes tratamentos, como rouquidão, odinofagia e afonia que envolvem dificuldades na comunicação oral e/ou deglutição desses pacientes (CAMPOS; LEITE, 2010).

Porém, essa temática ainda não tem sido abordada na graduação de Fonoaudiologia como deveria. Atrelada à insuficiência na formação evidencia-se a carência da assistência fonoaudiológica em Oncologia na região da Paraíba, o que suscitou na criação, em 2017, da Liga Acadêmica de Fononcologia (LIAFO) da UFPB. A Liga tem como principal objetivo de ampliar os conhecimentos na área e realizar estratégias acadêmicas articuladas entre a universidade e a comunidade.

Visto que alguns membros do grupo do Estágio Supervisionado em Saúde Coletiva integram a LIAFO, a ideia de realizar uma ação alusiva ao Dia Mundial do Câncer se fortaleceu. $\mathrm{O}$ dia 04 de fevereiro tem como finalidade conscientizar e disseminar informações sobre prevenção e controle do câncer, educando a população sobre a doença, além de influenciar governos e indivíduos para que se mobilizem pelo controle do câncer evitando, assim, milhões de mortes a cada ano (INCA, 2020).

Diante do exposto, objetivou-se sensibilizar a comunidade sobre a Fononcologia, buscando prevenir novos casos de câncer e evidenciar a importância do fonoaudiólogo no cuidado ao paciente oncológico. 


\section{MÉTODO}

O presente estudo trata-se de um relato de experiência de uma ação educativa alusiva ao dia mundial do combate ao câncer. Atividade realizada por estudantes do Estágio Supervisionado em Saúde Coletiva, componente curricular do Curso de Graduação em Fonoaudiologia da UFPB. A mesma ocorreu no mês de fevereiro do corrente ano, na sala de espera de uma USF situada na área de abrangência do Distrito Sanitário V, do município de João Pessoa-PB.

A fim de planejar a ação, o grupo de cinco discentes, sob a orientação da docente responsável pela disciplina, teve um momento de aprofundamento teórico. Cada membro escolheu um artigo científico a respeito da Fonoaudiologia e Oncologia para ler e apresentar aos demais, ampliando os conhecimentos sobre o tema. Em seguida, foi decidido como seria o passo a passo da ação educativa, desde os insumos que seriam necessários até o que cada um iria explanar na USF.

É relevante mencionar que tal atividade baseou-se na filosofia freireana, a qual considera a horizontalização da educação ao tornar todos os envolvidos partícipes, igualitariamente, da construção de conhecimento (FREIRE, 1996).

Produziu-se um cartaz informativo para ilustrar a temática da ação e facilitar a compreensão dos participantes. Nele foi desenhada uma imagem contendo a cavidade nasal, seios paranasais, cavidade oral, laringe e faringe que são as regiões atingidas pelos tumores de cabeça e pescoço, e escrevemos as principais áreas da fonoaudiologia que estão relacionadas com a Oncologia.

No primeiro momento, com ajuda da preceptora da USF, foram feitas as devidas apresentações da professora e estagiárias, a fim de conhecer a dinâmica do ambiente e as particularidades dos usuários da área adscrita.

A sondagem oral marcou o pontapé inicial da ação. Logo, abarcando o conhecimento do público-alvo foi explicitado sobre as áreas de atuação do fonoaudiólogo, tais como a disfagia, voz, audição, linguagem e saúde coletiva e como esse profissional presta atendimento aos pacientes oncológicos. Foram elencados os fatores de riscos e os cuidados preventivos em relação ao câncer no 
geral, sendo utilizada uma linguagem clara, sem termos técnicos com fins de facilitar a compreensão de todos.

Cabe enfatizar que, como na maioria das ações de educação em saúde, em especial àquelas que se fundamentam em Paulo Freire, a participação ativa de todos é essencial. Portanto, durante toda a atividade os usuários puderam fazer perguntas e tirar suas dúvidas sobre o assunto, o que moldou positivamente o processo de aprendizado.

Ademais, tratando-se de uma atividade educativa no âmbito da saúde coletiva, nada melhor do que trabalhar a interprofissionalidade. Bispo, Tavares e Tomaz (2014) trouxeram em seu estudo alerta sobre o desconhecimento desse tema pelos profissionais, desde a teoria até a prática, já que os sujeitos não tiveram uma formação acadêmica voltada para a interdisciplinaridade e nenhum contato do tipo capacipatório no campo profissional, enaltecendo a necessidade da Educação Permanente em Saúde. Em contrapartida ao estudo, houve a colaboração de estagiários do curso de nutrição, complementando as informações e sensibilizando os usuários em relação à alimentação saudável para a prevenção do câncer.

\section{RESULTADOS}

A escolha da sala de espera para realização da ação se mostrou ideal, pois é um espaço privilegiado devido ao grande número de usuários que se faziam presentes e por contribuir para diminuir o desgaste causado pela frequente demora do atendimento. Além disso, gera aproximação com a comunidade, permite conhecer a realidade dos que ali são atendidos e constrói um momento de partilha, uma vez que os usuários ficam à vontade para relatar suas angústias. Talvez seja uma das melhores maneiras de estabelecer vínculos de confiança entre os profissionais e usuários, determinando a humanização do atendimento e tomadas de decisão mais adequadas.

A ação desenvolvida em sala de espera se respalda na Política Nacional de Humanização do SUS, proporcionando ao usuário a troca e construção de saberes e 
uma escuta qualificada sobre questões da saúde do mesmo e permite aos acadêmicos o contato com outros profissionais da rede, levando o aluno, a refletir sobre as necessidades locais, viabilizando a elaboração e organização de ações de promoção de saúde voltadas para as necessidades e interesses da população (REIS et al., 2014).

Legitimando a reflexão anterior, autores referem que a sala de espera funciona como um espaço eficaz, em que as práticas de educação em saúde são ampliadas, potencializando discussões, reflexões e troca de saberes, onde todos podem participar e não apenas pessoas em risco de adoecer, o que contribui para o usuário se tornar ativo e corresponsável com sua saúde e qualidade de vida (ROSA; BARTH; GERMANI, 2011).

A partir da ação conseguiu-se instruir as pessoas acerca da importância de ter uma vida saudável e evitar alguns hábitos que se configuram em fatores de risco para o câncer. Boas medidas para prevenir ou retardar o desenvolvimento de câncer de cabeça e pescoço são cessar o tabagismo, limitar o consumo de álcool, evitar a exposição a fumo passivo e agentes carcinogênicos ambientais, fazer triagem para Papilomavírus Humano (HPV), manter boa saúde oral e bons hábitos alimentares, além de controlar o estresse (GALBIATTI et al., 2013). A intenção de conscientizar a comunidade a fazer escolhas e mudar hábitos nocivos é um dos resultados que se almeja ter alcançado, embora reconheçamos o quão difícil é.

Foi enaltecida a relevância do fonoaudiólogo no cuidado aos pacientes que já se encontram com o diagnóstico do câncer. Informando sobre a importância desse profissional nos casos de disfagia, que é uma das sequelas do tratamento oncológico, e o paciente acaba perdendo o prazer de se alimentar por via oral. Isso pode ocorrer independente do lugar do tumor se o paciente usar sonda e traqueostomia, para conseguir a volta dessa função é necessário o tratamento fonoaudiológico, visto que é o mais indicado para tratar desse sintoma.

Entre os tumores que afetam a voz, o de laringe tem grande impacto, pois em alguns casos o tratamento necessário é a laringectomia total (retirada da laringe), e esse paciente perde sua capacidade natural de produzir voz. É o fonoaudiólogo que auxiliará na escolha e na adaptação do método para produção vocal (VICENTE; OLIVERIA; SALES, 2012). Durante a ação foi explanado a respeito desses métodos, 
tais como a voz esofágica, prótese traqueoesofágica e laringe eletrônica. Alguns participantes conheciam, já haviam visto enquanto outros não tinham ideia de que isso seria possível.

Para a produção da voz esofágica ocorre a passagem do ar proveniente do meio externo para o segmento faringoesofágico (SFE). Esse ar é armazenado no esôfago e retorna vibrando o SFE, gerando a voz esofágica. É um procedimento exige controle motor e condições fisiológicas adequadas (VICENTE; OLIVERIA; SALES, 2012). Além disso, torna- se um método vantajoso por não ter custos e não precisar da utilização das mãos para sua produção, além de ser mais natural. Contudo, demora muito para ser aprendido e tem alta taxa de insucessos, o que pode fazer o paciente desistir.

A laringe eletrônica é um vibrador movido à bateria ou pilha, o qual emite um estímulo sonoro contínuo, o aparelho é colocado em contato direto com o pescoço, e o som é transmitido ao trato vocal e transformado em fala por meio da articulação, segundo Figueiredo, Wannimacher e Vicente (2000). Esta é uma boa opção para pessoas de baixa renda que não consegue desenvolver voz esofágica, pois a laringe eletrônica está disponível no Sistema Único de Saúde (SUS).

As próteses são implantadas cirurgicamente e consistem de uma válvula unidirecional colocada em uma fístula traqueoesofágica, para produção vocal o próprio paciente oclui o traqueostoma, essa oclusão leva o ar para a fístula que o direciona para o esôfago e dali para a cavidade oral onde é articulado, sendo utilizado o ar pulmonar (CLETO, 2000). A voz é ótima, mas devido ao custo da prótese traqueoesofágica ainda é pouco empregada no Brasil.

No que concerne à audição, foi citado que durante o tratamento do câncer às vezes é necessário que os pacientes façam uso de medicamentos ototóxicos, os quais podem apresentar como reação adversa a perda da audição. Relatou-se ser imprescindível o acompanhamento auditivo junto ao fonoaudiólogo para poder prevenir, diagnosticar e intervir, caso ocorram alterações na audição. Existindo a necessidade da realização de avaliações audiológicas e otorrinolaringológicas pela utilização de medicamentos ototóxicos (COSTA; BUSS, 2009).

Constatou-se que nenhum usuário que estava presente na ação educativa sabia da existência de medicamentos que prejudicam a audição e sequer fazia a 
correlação entre o câncer e a perda auditiva devido à terapêutica medicamentosa. De acordo com César et al. (2016), a promoção de saúde envolve a necessidade de que o profissional da saúde construa com a comunidade espaços coletivos para o desenvolvimento de práticas educativas que atinjam as necessidades e expectativas da comunidade, para melhor qualidade de vida e saúde. É num momento como esse que reconhecemos ser fundamental disseminar informação fidedigna, de orientar a comunidade de maneira clara e assim provocar algo tão importante: o autocuidado.

Quanto à linguagem e comunicação do paciente foi mencionado que o câncer no Sistema Nervoso Central (SNC) pode influenciar e causar alterações. Em estudo realizado com 70 pacientes, sendo crianças e adolescentes, em um hospital oncológico, 44,3\% tinham distúrbios de deglutição, 34,3\%, alterações na linguagem receptiva, 38,6\%, alterações na linguagem expressiva, 31,4\%, alterações na fala e $5,7 \%$, alterações vocais (COÇA et al., 2017).

Sendo papel do fonoaudiólogo reabilitar e/ou readaptar as funções alteradas, melhorando a qualidade de vida, cabe a ele avaliar, diagnosticar, identificar e intervir nas alterações para que o paciente consiga se comunicar e se alimentar de maneira segura. A possibilidade de comunicação pode evitar que esses pacientes se afastem dos familiares e amigos o que poderia levar a depressão, transtorno psiquiátrico mais comum em pacientes com câncer (BOTTINO; FRÁGUAS; GATTAZ, 2009).

Indubitavelmente, lidar com o diagnóstico do câncer é um processo difícil e lento, por isso é imperativo ter o apoio não só em casa com os familiares, mas também nas unidades de saúde e hospitais. Acredita-se que nesses locais quem dará esse suporte serão os profissionais de saúde, tendo um olhar humanizado e atento as singularidades de cada pessoa. Acresce-se que o trabalho do fonoaudiólogo na saúde mental é primordial, uma vez que é o mais habilitado para subsidiar uma aliada poderosa contra a depressão: a comunicação dos pacientes.

O trabalho em grupo, como o realizado na atividade, permite que os sujeitos despertem para assuntos desconhecidos e/ou inconscientes, discutam, reflitam, e transfiram para a vida conhecimentos importantíssimos que os auxiliarão a serem agentes de sua própria saúde (SOUZA et al., 2016). Como já esperado, a atividade educativa realizada na USF ampliou não somente o conhecimento dos usuários, mas também de cada estagiário, sobretudo acerca da ausência de saberes em relação à 
Fonoaudiologia. Ainda há muito que fazer para enaltecer essa profissão tão multifacetada na APS.

O fato é que os usuários não conheciam muito sobre a atuação do fonoaudiólogo na área da Oncologia. Entretanto, no desenrolar da ação verificou-se que conseguiram apreender as informações a respeito do trabalho da Fonoaudiologia, tendo suas dúvidas sanadas de maneira satisfatória. $O$ uso do cartaz (figura 1) possibilitou ilustrar melhor o motivo da ação e auxiliou na capitação da atenção dos usuários.

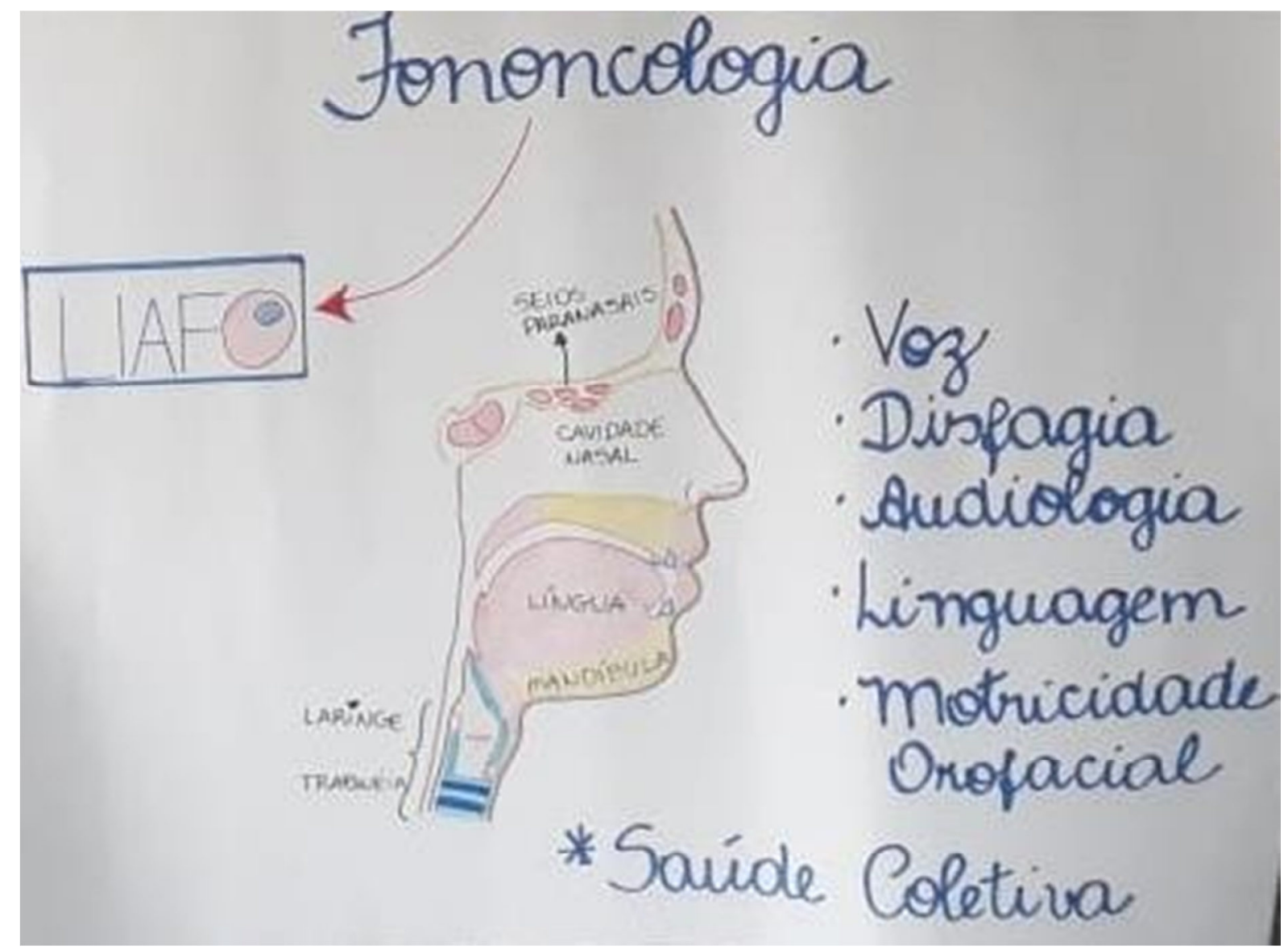

Figura 1 - Cartaz produzido para ação.

Singular. Essa talvez seja a melhor palavra para definir a atividade educativa realizada. O contato com os usuários possibilitou novos olhares e saberes. Ouvi-los, conhecer mais sobre eles, suas realidades e anseios dá sentido a uma ação que visa a troca, a partilha. E assim, desconstruindo paradigmas entre comunidade e 
universidade, criou-se um vínculo de confiança, fortalecendo a prática do Estágio, edificando o fazer saúde.

Estratégias de integração entre os serviços de saúde e as Instituições de Ensino Superior (IES) parecem ser alternativas que possibilitam mudar o contexto da Fonoaudiologia no SUS, favorecendo a ampliação da responsabilidade pública e da relevância social da universidade, na medida em que traz para o cenário da educação o conjunto das referências centrais do Sistema vigente: descentralização da gestão, integralidade da atenção e fortalecimento do controle da sociedade sobre as ações, serviços e sistema de saúde (LEMOS; BAZZO, 2007). No estudo de Casanova, Moraes e Ruiz-Moreno (2010, p. 219-234) constatou que "a aproximação a cenários de prática profissional durante os cursos, que incluem serviços de saúde, escolas, comunidade, constitui um relevante aspecto formativo na área da saúde". 


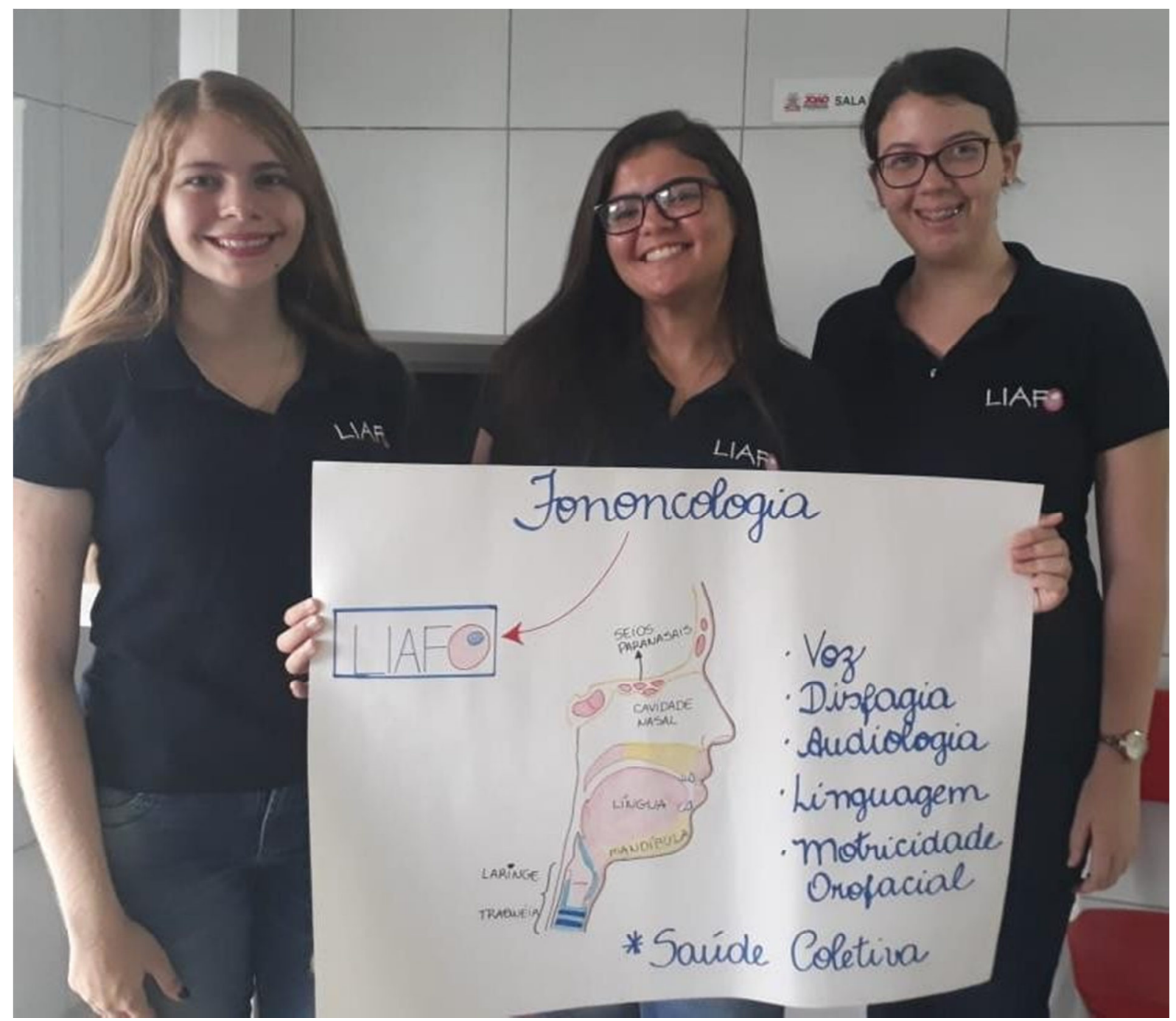

Figura 2 - Estagiárias e membros da LIAFO. 


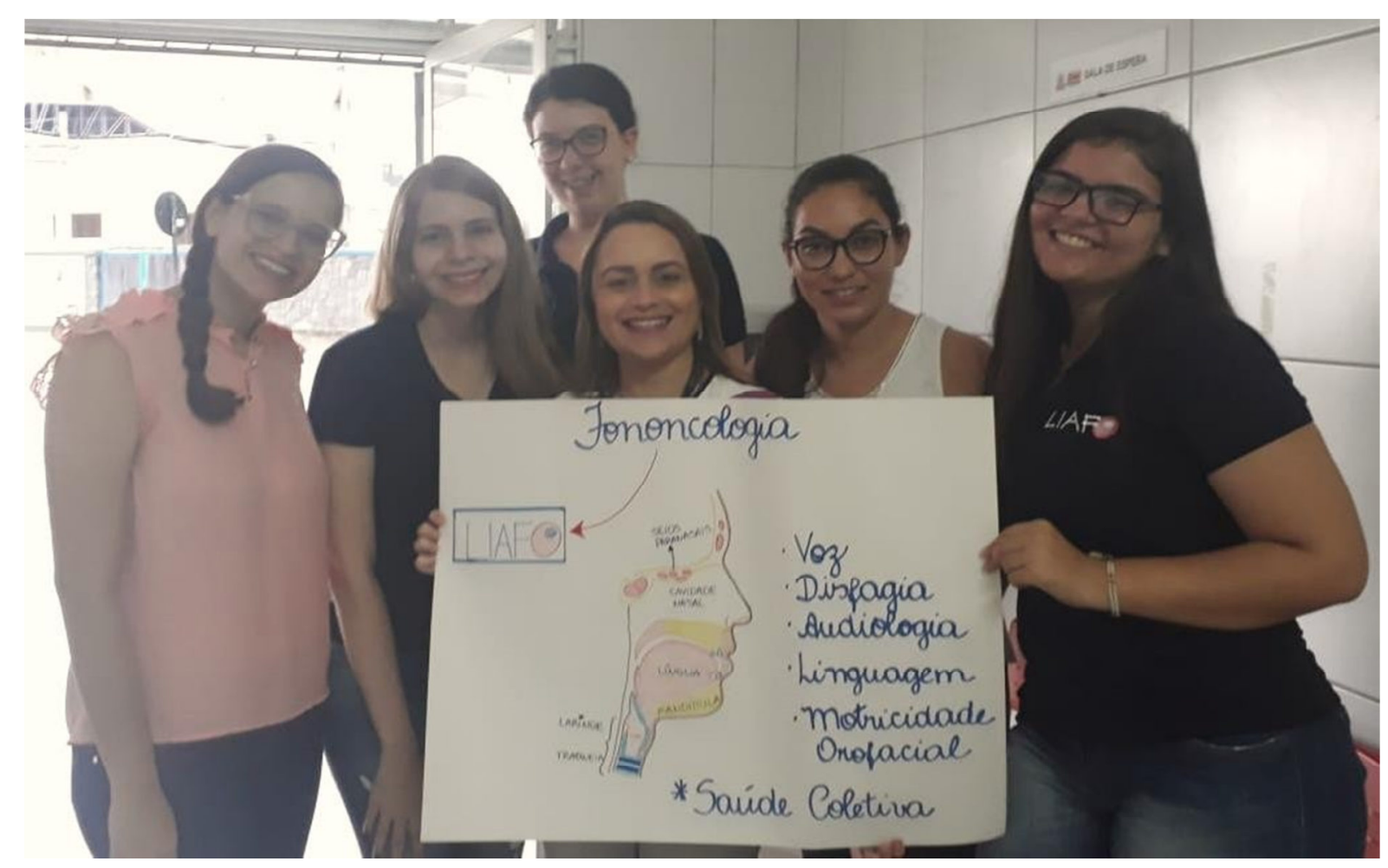

Figura 3 - Grupo do Estágio Supervisionado em Saúde Coletiva.

\section{CONCLUSÃO}

Um grande passo foi dado, tanto para o grupo de Estágio Supervisionado em Saúde Coletiva quanto para todos os integrantes da USF na qual se realizou a atividade educativa sobre Fononcologia. Quando é referido todos, não assinalamos somente os usuários, abrangem-se a recepcionista, Agentes Comunitários de Saúde, alguns profissionais como a odontóloga, enfermeira e médica da Unidade. É um ganho mútuo, pois se trata de uma via de mão dupla, aonde cada participante no vai e vem dos saberes aprende e reaprende, especialmente a respeitar os limites do outro.

No cenário da sala de espera, foi possível promover saúde e perceber o quanto a Fonoaudiologia, não apenas na área da Oncologia, mas geral, ainda precisa ser difundida e consolidada na APS. Ademais, a experiência de formar um 
grupo heterogêneo, no qual se pôde empregar a empatia e a humanização nas entrelinhas da temática que estava sendo abordada, superaram as expectativas de ambas as partes envolvidas nesse processo de aprendizado contínuo.

Adicionada à vivência da educação em saúde tem-se o estímulo da criatividade dos estagiários durante todo o planejamento e execução da ação. $\mathrm{Na}$ verdade, a intenção da docente responsável foi o despertar do senso críticoreflexivo, que é essencial para o discente da área da saúde, baseando-se no quadrilátero da formação e com fins de atuar na APS.

\section{REFERÊNCIAS BIBLIOGRÁFICAS}

Bispo, E. P. F.; Tavares, C. H. F.; Tomaz, J. M. T. Interdisciplinaridade No Ensino Em Saúde: O Olhar Do Preceptor Na Saúde Da Família. Interface, Botucatu, V. 18, N. 49, P. 337- 350, Jun. 2014. Disponível Em: <Http://Www.Scielo.Br/Scielo.Php?Script=Sci_Arttext\&Pid=S141432832014000200337\&Lng=En\&Nrm=Iso>. Acesso Em: 01 Mar. 2020.

Bottino, S. M. B.; Fraguas, R.; Gattaz, W. F. Depressão E Câncer. Revista De Psiquiatria Clínica, São Paulo, V. 36, Supl. 3, P. 109-115, 2009. Disponível Em: $<$ Http://Www.Scielo.Br/Scielo.Php?Script=Sci_Arttext\&Pid=S0101-

60832009000900007\&Lng=En\&Nrm=Iso>. Acesso Em: 29 Fev. 2020.

Campos, R. J. D. S.; Leite, I. C. G. Qualidade De Vida E Voz Pós-Radioterapia: Repercussões Para A Fonoaudiologia. Revista Cefac, São Paulo, V. 12, N. 4, P. 671-677, Ago. 2010. Disponivel Em: <Http://Www.Scielo.Br/Scielo.Php?Script=Sci_Arttext\&Pid=S151618462010000400017\&Lng=En\&Nrm=Iso>. Acesso Em: 22 Fev. 2020.

Casanova, I. A.; Moraes, A. A. De A.; Ruiz-Moreno, L. O Ensino Da Promoção Da Saúde Na Graduação De Fonoaudiologia Na Cidade De São Paulo. Pró-Posições, Campinas, V. 21, N. 3 , P. 219-234, Dez. 2010.

César C. P. H. A. R. Et Al. Promoção Da Saúde E Fonoaudiologia: Possibilidades De Atuação. In: Paranhos L. R., Sordi C., César C. P. H. A. R., Organizadores. Coletâneas Em Saúde. São José Dos Pinhais: Editora Plena; V. 4, P. 61-70, 2016.

Cleto, M. L. S. Reabilitação Na Laringectomia Total. In Barros, A. P. B.; Arakawa, L.; Tonini M.D.; Carvalho, V. A. Fonoaudiologia Em Cancerologia. São Paulo: Fundação Oncocentro De São Paulo, 2000.

Coça, K. L. Et Al. Prevalência De Distúrbios Da Comunicação, Deglutição E Motricidade Orofacial Em Crianças E Adolescentes No Momento Da Matrícula Em Um Hospital Oncológico. Codas, São Paulo, V. 30, N. 1, E20170123, 2018. Disponível Em: $<$ Http://Www.Scielo.Br/Scielo.Php?Script=Sci_Arttext\&Pid=S2317-

17822018000100307\&Lng=En\&Nrm=Iso>. Acesso Em: 23 Fev. 2020.

Costa, J. C.; Buss, C. H. Análise De Prontuários De Pacientes Oncológicos Quanto Ao Monitoramento Auditivo. Revista Cefac, São Paulo, V. 11, N. 2, P. 323-330, Jun. 2009. Disponível $<$ Http://Www.Scielo.Br/Scielo.Php?Script=Sci_Arttext\&Pid=S1516- 
18462009000200018\&Lng=En\&Nrm=Iso>. Acesso Em: 01 Mar. 2020.

Figueiredo, E. S.; Wannmacher, L.; Vicente, L. C. Inteligibilidade De Fala Eletrolaríngea De Laringectomizados Totais. In Barros, A. P. B.; Arakawa, L.; Tonini M.D.; Carvalho, V. A. Fonoaudiologia Em Cancerologia. São Paulo: Fundação Oncocentro De São Paulo, 2000.

Freire, P. Pedagogia Da Autonomia: Saberes Necessários À Prática Educativa. São Paulo: Paz E Terra, 1996.

Galbiatti, A. L. S. Et Al. Câncer De Cabeça E Pescoço: Causas, Prevenção E Tratamento. Brazilian Journal Of Otorhinolaryngology, São Paulo, V. 79, N. 2, P. 239-247, Abr. 2013.

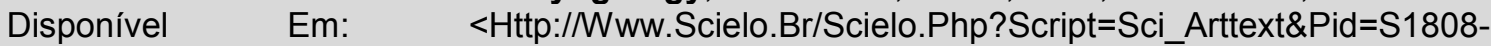
86942013000200018\&Lng=En\&Nrm=Iso>. Acesso Em: 25 Fev. 2020.

Instituto Nacional Do Câncer (Inca). Câncer. 2019. Disponível Em: <Https://Www.Inca.Gov.Br/O-Que-E-Cancer>. Acesso Em: 22 Fev. 2020.

Instituto Nacional Do Câncer (Inca). Dia Mundial Do Câncer. 2020. Disponível Em: <Https://Www.Inca.Gov.Br/Campanhas/Dia-Mundial-Do-Câncer>. Acesso Em: 21 Fev. 2020.

Lemos, M.; Bazzo, L. M. F. Formação Do Fonoaudiólogo No Município De Salvador E Consolidação Do Sus. Ciência \& Saúde Coletiva, Rio De Janeiro, V. 15, N. 5, P. 2563-2568, Ago. 2010. Disponível Em: <Http:/Www.Scielo.Br/Scielo.Php?Script=Sci_Arttext\&Pid=S141381232010000500030\&Lng=En\&Nrm=Iso>. Acesso Em: 26 Fev. 2020.

Limeira, M. E. O. Et Al. Sala De Espera Como Ferramenta Para Educação Em Saúde Na Atenção Básica. Revista Brasileira De Ciências Da Saúde, João Pessoa, V. 18, P. 59-62, 2014.

Reis F. V. Et Al. Educação Em Saúde Na Sala De Espera - Relato De Experiência. Revista Médica De Minas Gerais, Belo Horizonte, V. 24, P. 32-36, 2014.

Rosa, J., Barth, P. O., Germani, A. R. M. A Sala De Espera No Agir Em Saúde: Espaço De Educação E Promoção À Saúde. Revista Perspectiva; Erechim, V.35, N.129, P. 121-130, Mar. 2011.

Santos, C.; Borges, A. M. Educação Em Saúde: Um Relato De Experiência Sobre Sala De Espera. In: Congresso Brasileiro Interdisciplinar De Promoção Da Saúde, 2016, Santa Cruz Do Sul, Rs. Anais (Online). Disponível Em: $<$ Https://Online.Unisc.Br/Acadnet/Anais/Index.Php/Cbips/Article/View/15938>. Acesso Em: 21 Jan. 2020.

Souza, A. P. R. Et Al. O Grupo Na Fonoaudiologia: Origens Clínicas E Na Saúde Coletiva. Revista Cefac, São Paulo, V. 13, N. 1, P. 140-151, Fev. 2011.

Vicente, L. C. C. O Convívio Interdisciplinar E O Papel Da Fonoaudiologia. In Barros, A. P. B.; Arakawa, L.; Tonini M.D.; Carvalho, V. A. Fonoaudiologia Em Cancerologia. São Paulo: Fundação Oncocentro De São Paulo, 2000.

Vicente, L. C. C.; Oliveria, P. M.; Sales P. V. Laringectomia Total: Avaliação E Reabilitação. In: Carvalho, V.; Barbosa, E. A. Fononcologia. Rio De Janeiro: Revinter, 2012. 